\title{
Steel Fibres as Reinforcement in Post-tensioned Flat Slabs
}

\author{
Stine Maria Frøiland Jensen, Jan Arve Overli* \\ Department of Structural Engineering, Norwegian University of Science and Technology, Norway
}

Copyright (C) 2015 by authors, all rights reserved. Authors agree that this article remains permanently open access under the terms of the Creative Commons Attribution License 4.0 International License

\begin{abstract}
This paper presents a numerical investigation of a post-tensioned flat slab without conventional longitudinal reinforcement; only steel fibres were employed to ensure sufficient ductility and shear capacity of the slab. Results were taken from a reported experiment conducted on a full scale steel fibre-reinforced flat slab $(0.38 \%$ fibre content) which was tested until failure, undergoing a ductile bending failure. A nonlinear finite element analysis was employed to study the experiment, including the ultimate state. A parametric study was performed using the numerical model to investigate the influence of the tensile behaviour of steel fibre-reinforced concrete (SFRC) on the structural response. The model proved to be relatively sensitive to changes in the tensile behaviour, but the differences were not prominent until entering the nonlinear area of the load-displacement curve. A constant curve with tensile stress equal to the residual tensile strength of the SFRC provided a robust numerical model and results on the conservative side. Including a peak stress with a multilinear tensile curve provided a less stable analysis but more accurate results. However, the model behaviour was stiffer than the experiment, providing too small deformations at failure. Nevertheless, the numerical model was able to display the ductile bending failure mode and moment redistribution.
\end{abstract}

Keywords Steel Fibre Reinforcement, Post-tensioning, Flat Slab, Nonlinear Finite Element Analysis

\section{Introduction}

Concrete is one of the most important building materials in civil engineering, due to its simple production, its high compressive strength and versatility in form and application. Some major disadvantages of concrete, however, are its brittleness and low tensile strength, resulting in poor resistance to crack propagation. Adding steel fibres to the concrete can provide a solution to these challenges and improve the mechanical properties of the concrete significantly. The main task of the fibres is to bridge cracks and transfer tensile stresses across cracks. This leads to better crack control and smaller crack widths, in addition to increased flexural stiffness, which are desirable properties in the service limit state [1]. Regarding the ultimate limit state, the fibre provides larger ductility, toughness (residual load carrying capacity) and shear resistance [2]. In addition to improved mechanical properties, important benefits of steel-fibre reinforced concrete (SFRC) include efficiency and reduced costs during construction. Valuable labour-time can be saved by using SFRC as placement of reinforcement is not required, making SFRC an economically favourable and more efficient solution.

The tensile behaviour of SFRC is characterised by a distinct and stable residual tensile strength after cracking. In design codes and guidelines the characteristic residual tensile stress taken at a crack width of $2.5 \mathrm{~mm}, f_{\text {ftk }, \text { res } 2.5 \text {, often }}$ constitutes the basis for design in service and ultimate limit states $[3,4]$. The residual tensile strength must as of today be determined through bending tests of standard test beams, as described in [5]. The residual tensile strength and other material properties of SFRC are dependent on the fibre content as well as the distribution and orientation of the fibre in the concrete. The fibre orientation factor defines the efficiency of bridging in terms of amount of fibres in a cracked section and fibre orientation effects [6]. In general, the fibre orientation factor increases for smaller dimensions and for more homogeneous fibre distribution [1]. Due to the flow of fresh concrete, a higher orientation factor will be obtained in the flow direction, particularly in self-compacting concrete. Increased flow and a longer flow distance have been reported to lead to a better alignment of fibres [7]. Near the walls of moulds the fibres are not free to rotate, and frictional restraints along the walls of the mould align the fibres parallel to the walls.

Until today the use of SFRC has mostly been limited to shotcrete in tunnel linings, pavements and slabs-on-ground [8]. Application in load carrying structures has been prevented due to lack of regulations, although considerable research has been done on the topic during the last decade[9, 10]. Numerous experiments have been conducted, both laboratory tests and full scale field tests [11-13], largely 
focusing on fibre in load carrying concrete structures, gaining relatively good results. SFRC has also successfully been employed in post-tensioned structural elements with no mild reinforcement [14]. One important observation from these tests is that the residual tensile strength of SFRC varies considerably from small test beams to full scale structures. The reason for this is not yet fully understood and represents a major obstacle in making regulations for SFRC [15]. Factors influencing the scaling factor between small and full scale tests are the execution and casting procedure of SFRC. Size, type of structure, formworks, reinforcement layout and flow distance of the concrete have influence on the fibre distribution and orientation.

This study contains numerical investigations of a reported experiment conducted on a full scale SFRC flat slab, which was tested to failure. The slab was post-tensioned but had no conventional longitudinal reinforcement; only steel fibres were employed to ensure sufficient ductility and shear capacity. Nonlinear structural analyses have been performed with the finite element code DIANA [16]. The aim of the numerical investigations is to provide a verification of the executed experiment and to explore how SFRC is implemented in a finite element model. A parametric study has been conducted to obtain the optimal material parameters for modelling tensile behaviour of SFRC.

\section{Experimental Study}

The full scale SFRC flat slab was post-tensioned but contained no mild reinforcement. The slab was subjected to evenly distributed load until collapse occurred, to observe the contribution of fibre in the ultimate limit state. All results from the experiment and other relevant information used in this study were taken from [17].

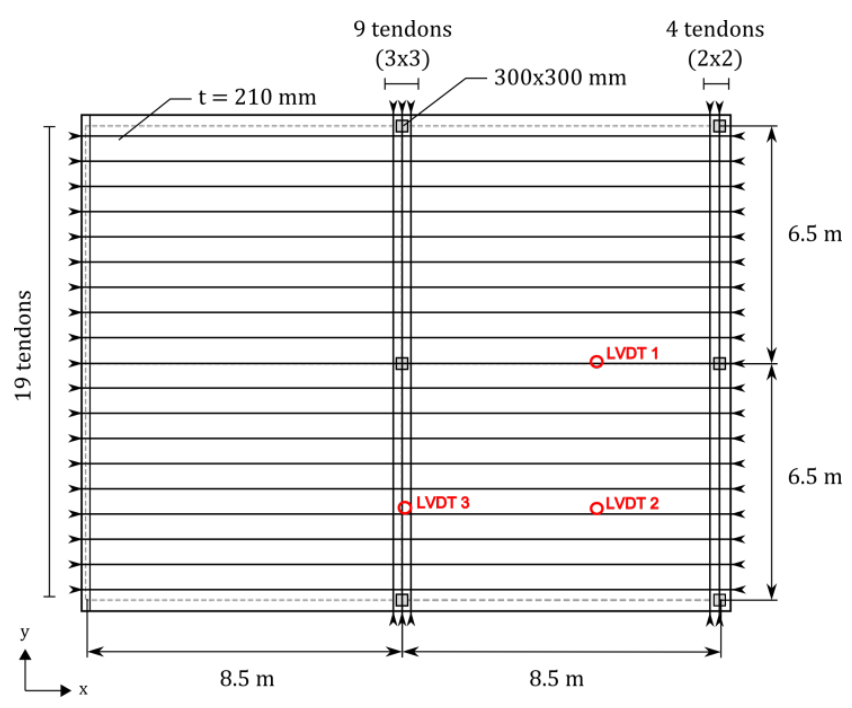

Figure 1. Geometry of test slab including LVDT positions

\subsection{Geometry and Test Set-up}

The slab measured $17.3 \mathrm{mx} 13.4 \mathrm{~m}$ and was $210 \mathrm{~mm}$ thick.
It was supported by six columns and one wall, giving spans with effective lengths $8.5 \mathrm{~m}$ and $6.5 \mathrm{~m}$, respectively. The full geometry of the slab is shown in Figure 1. The column cross-sections were $300 \mathrm{~mm} \times 300 \mathrm{~mm}$ and the wall thickness was $200 \mathrm{~mm}$. The SFRC used was a self-compacting concrete with fibre content of $30 \mathrm{~kg} / \mathrm{m}^{3}$ or 0.38 volume $\%$ steel fibres of length $50 \mathrm{~mm}$ and diameter $0.8 \mathrm{~mm}$ and hooked ends from KrampeHarex [18].
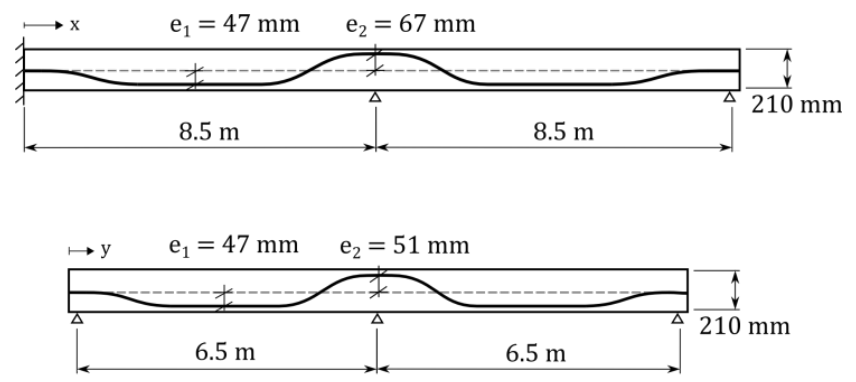

Figure 2. Tendons profile in the longitudinal direction

The slab was post-tensioned in both directions with curved single strand tendons with diameter $16 \mathrm{~mm}$, with distribution as shown in Figure 1. The concentrated tendons above the columns were placed in bundles of two and three, respectively. The curved tendon profiles are shown in Figure 2 for each direction. The tendons were unbonded, which was achieved by greasing and plastic sheathing to provide minimal friction. Three LVDT sensors were mounted to measure the deflections of the slab, in the positions shown in Figure 1. LVDT 1 and 2 were placed in the critical span where maximum deflection would occur according to static beam formulas; $3 \mathrm{~L} / 8$ from the edge of the slab. All measurements started at zero when the experiment started, thus only the response from the water load was measured.



Figure 3. Failure mode of test slab showing the yield lines

The slab was loaded with water to ensure an evenly distributed and steadily increasing load. The water was pumped into a formwork on top of the slab until collapse 
occurred, at a water load $6.5 \mathrm{kN} / \mathrm{m}^{2}$. The dead weight of the slab was $5.04 \mathrm{kN} / \mathrm{m}^{2}$. Each tendon was post-tensioned with a force of $220 \mathrm{kN} 5$ days after casting, and the post-tensioning force after losses was assumed to be $200.9 \mathrm{kN}$. The experiment was conducted after 29 days. During testing there was no visual indication of crack growth at the outer parts of the bottom face of the slab. Due to safety reasons there was no visual inspection of crack growth around the interior column. The top face was covered with a waterproof membrane. Hence, it is difficult to describe where the collapse started other than observing significant increase of deflections close to failure load.

Failure occurred due to bending moment in the exterior span at a water height of $65 \mathrm{~cm}$, at a failure load considerably higher than expected. The failure mode was a characteristic ductile failure with large deflections and rotations before collapse, see Figures 3 and 4, and it was predicted by [17] on the basis of yield line theory. The punching shear capacity proved to be sufficient, due to the contribution of the fibre. Further, the test results showed that significant moment redistribution occurred during the experiment, hence the SFRC had sufficient ductility for plastic deformation and moment distribution to occur.

\subsection{Material Properties}

Six cylinders with a diameter of $100 \mathrm{~mm}$ and a height of $200 \mathrm{~mm}$ and six standard beams were cast from the same SFRC batch as used in the slab. The standard beams had a quadratic cross section of $150 \mathrm{~mm}$ and a free span of 500 $\mathrm{mm}$. In addition 15 standard beams were sawn from the slab after the experiment. The cylinders were tested in uniaxial compression tests which resulted in a characteristic compressive strength of $f_{c k}=47.4 \mathrm{MPa}$ and a mean compressive strength of $f_{c m}=49.3 \mathrm{MPa}$. The standard beams were subjected to bending tests to determine the residual bending tensile strength of the SFRC, and both the characteristic values $f_{f t k, r e s 2.5}$ and the mean values $f_{\text {ftm, res } 2.5}$ were found. The characteristic values was calculated according to [5] as $f_{f t k, r e s 2.5}=f_{\text {ftm, res2. } 5-1.6}-\mathrm{s}$, where $s$ is the standard deviation. The six cast beams were subjected to 3-point bending tests for notched beams [4] while for the un-notched sawn beams from the slab a 4-point bending test was used [13].The results from the bending tests are given in Table 1.

Table 1. Residual bending tensile strength of SFRC, from bending tests

\begin{tabular}{ccc}
\hline & $\mathrm{f}_{\mathrm{ftk}, \mathrm{res} 2.5}[\mathrm{MPa}]$ & $\mathrm{f}_{\mathrm{ftm}, \mathrm{res} 2.5}[\mathrm{MPa}]$ \\
\hline 3-point bending test [4] & 0.97 & 1.54 \\
$\begin{array}{c}\text { 4-point bending test [13] } \\
\text { 4-point bending test, } \\
\text { calculated after [4] }\end{array}$ & 0.45 & 1.10 \\
\hline
\end{tabular}

The fibre orientation factor was approximately the same for all the sawn beams from the slab. The cast test beams, however, displayed a significantly higher fibre orientation factor, presumably because the small dimensions of the formwork provided a more uniform fibre distribution in the cast beams. Therefore, the residual tensile strength from the sawn beams was considered more representative for the experiment, and was employed for the analyses in this study. The material properties of the concrete (taken from Eurocode 2 [19] on the basis of the obtained compressive strength) and the post-tensioning reinforcement are summarised in Table 2.

Table 2. Material properties of the concrete and tendons

\begin{tabular}{ccc|ccc}
\hline \multicolumn{1}{c|}{ Concrete } & & & Tendons & & \\
\hline $\begin{array}{c}\text { Compressive } \\
\text { strength }\end{array}$ & $\mathrm{f}_{\mathrm{ck}}$ & $47.7 \mathrm{MPa}$ & Yield strength & $\mathrm{f}_{\mathrm{p} 0.1 \mathrm{k}}$ & $1670 \mathrm{MPa}$ \\
& $\mathrm{f}_{\mathrm{cm}}$ & $49.3 \mathrm{MPa}$ & Ultimate stre & $\mathrm{f}_{\mathrm{pk}}$ & $1860 \mathrm{MPa}$ \\
Tensile strength & $\mathrm{f}_{\mathrm{ctm}}$ & $3.8 \mathrm{MPa}$ & Net diameter & $\Phi$ & $16 \mathrm{~mm}$ \\
Density & $\rho_{\mathrm{c}}$ & $24 \mathrm{kN} / \mathrm{m}^{3}$ & Cross section & $\mathrm{A}_{\mathrm{p}}$ & $150 \mathrm{~mm}^{2}$ \\
Elastic modulus & $\mathrm{E}_{\mathrm{c}}$ & $36000 \mathrm{MPa}$ & E-modulus & $\mathrm{E}_{\mathrm{s}}$ & $195 \mathrm{GPa}$ \\
Poisson's ratio & $v$ & 0.2 & & & \\
\hline
\end{tabular}

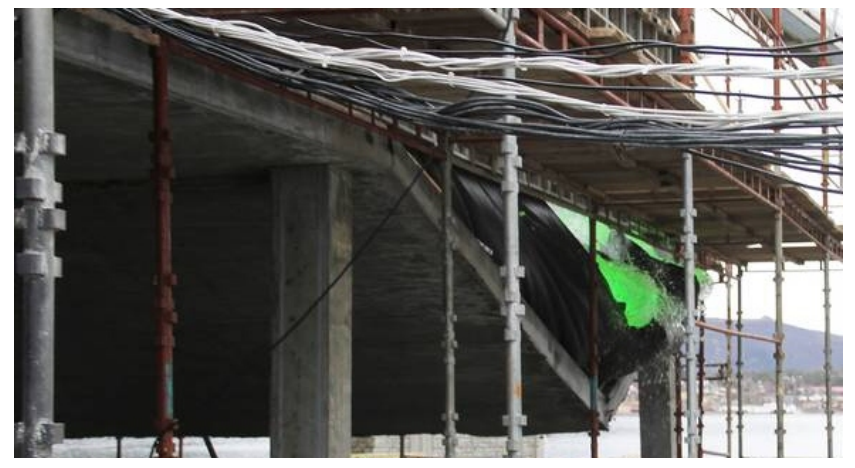

Figure 4. Test slab at the moment of collapse [20]

\section{Numerical Model}

In this section, the numerical model of the flat slab is presented. The slab was modelled using the finite element code DIANA [16] which is based on the displacement-method and well developed for nonlinear analysis of reinforced concrete structures.

\subsection{Material Models}

Concrete in compression is characterised by a nonlinear pressure-dependent behaviour. A total strain approach with a multilinear stress-strain curve given by Eurocode 2 [19] was used for the compressive behaviour, assuming no effect of lateral confinement and cracking. The low fibre content of $0.38 \%$ was assumed not to affect the properties in compression. The steel fibres were added by including the residual tensile strength in the constitutive model in tension. Constant and multilinear tensile models were employed, 
and a parametric study was performed to find the optimal tensile properties. Furthermore, a smeared crack approach was employed in combination with a total strain rotating crack model. This crack model allows cracks to rotate as the principal strain direction changes. The post-tensioning reinforcement was modelled as elastic-perfectly plastic and the yield limit was set to be the ultimate strength of the steel, $f_{p k}=1860 \mathrm{MPa}$. The slab measured $17.3 \mathrm{mx} 13.4 \mathrm{~m}$ and was $210 \mathrm{~mm}$ thick. It was supported by six columns.

\subsection{Finite Element Model}

Due to symmetry, only half of the slab was modelled. The slab model measured $17 \mathrm{~m} \times 6.5 \mathrm{~m}$ and included only the supports and restrained against vertical displacement while the connection to the wall was assumed to be fixed. To avoid numerical problems and large stress concentrations at the point supports, the elements above the columns were made linear elastic. All material properties are given in Table 2, and mean values were employed. The tendons were given curved profiles as shown in Figure 2, and the bundles were modelled as single tendons with 2 and 3 times larger cross-sections, respectively. A post-tensioning force of $200.9 \mathrm{kN}$ was applied to each tendon, and the tendons were unbonded, assuming zero friction. The post-tensioning and the self- weight of the slab were applied as an initial load step, before the water pressure was applied stepwise.

The slab was meshed using quadrilateral, isoparametric curved shell elements with 8 nodes and five degrees of freedom per node; three translations and two rotations. A $2 \times 2$ quadratic Gauss integration scheme was used over the area of the element, while a 7-point Simpson integration scheme was employed in the thickness direction of the slab. A relatively fine mesh of 2838 elements with approximate size $200 \mathrm{~mm}$ was provided to give accurate results. The tendons were inserted as embedded reinforcement bars. Element results such as stresses and strains were taken from the integration points.

\subsection{Parametric Study of Tensile Behaviour}

A parametric study was performed to find an appropriate tensile stress-strain curve for implementation in the numerical analyses. In the literature a lot of research describes the tensile behaviour of SFRC both experimentally and numerically [21-23]. An important part in these studies was how to transform the crack width openings to a stress-strain relationship which is necessary in a smeared crack approach. The material model in DIANA describing the tensile behaviour is based on the theories by Hillerborg et al. on analysis of crack formation and crack growth in concrete by means of fracture mechanics and finite elements [24]. In the present work the shape of tensile curves from the sawn beams given by [17] were taken as a basis, as well as previous research such as [12]. They confirm well with the recommendations from RILEM TC 162-TDF, which is given in Figure 5 [23].

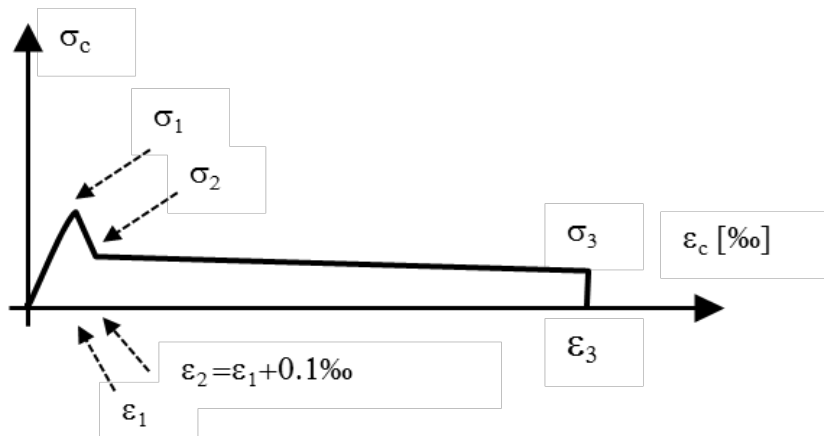

Figure 5. Tensile stress-strain relationship from RILEM TC 162-TDF [23]

Common for all the tensile curves from the sawn beam tests was that they displayed a distinct peak stress followed by a softening branch, before reaching a constant stress value equal to the residual tensile strength. An approximate value of $f_{\text {ftm, res } 2.5}=1.0 \mathrm{MPa}$ was used for the residual tensile strength in the analyses, based on the sawn beam tests. The tensile strengths from the bending tests ranged from approximately 3 to $5 \mathrm{MPa}$.

Table 3. Tensile parameters tested in numerical study

\begin{tabular}{cccccc}
\hline Analysis & 1 & 2 & 3 & 4 & 5 \\
\hline$\sigma_{1}[\mathrm{MPa}]$ & 1.0 & 3.8 & 3.8 & 2.7 & 2.7 \\
$\sigma_{2}[\mathrm{MPa}]$ & 1.0 & 1.0 & 1.0 & 1.0 & 1.0 \\
$\varepsilon_{2}[\% 0]$ & - & 0.39 & 1.0 & 0.5 & 0.5 \\
$\sigma_{3}[\mathrm{MPa}]$ & - & 1.0 & 1.0 & 1.0 & 0 \\
$\varepsilon_{3}[\% 0]$ & - & 10 & 10 & 10 & 10 \\
\hline
\end{tabular}

Five different tensile curves were investigated in this study, as presented in Figure 6 and Table 3. One was a highly simplified curve with a constant curve equal to the tensile residual strength, $f_{\text {ftm, res } 2.5}=1.0 \mathrm{MPa}$. Two curves had a peak stress equal to the mean tensile strength, $f_{c t m}=3.8 \mathrm{MPa}$ from Eurocode 2, but different post-peak slopes, before reaching a constant residual tensile strength. The last two curves were given a characteristic tensile strength according to Eurocode $2 \mathrm{f}_{\text {ctk }}=2.7 \mathrm{MPa}$ followed by a multilinear softening branch, whereas one was dragged to zero stress for the ultimate strain. The elastic modulus given in Table 2 was employed for all five alternatives.

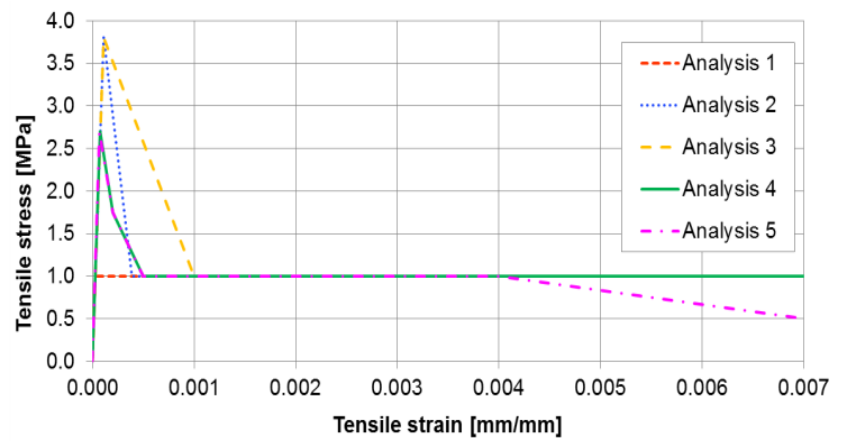

Figure 6. Tensile curves for SFRC implemented in the model 


\section{Comparison of Experimental and Numerical Results}

The results from the five different tensile stress-strain curves were compared to the experiment to see how the response of the model was affected. The main objective of the analyses was to capture the global response of the structure. In this section, the load-displacement curves from the various tensile models are discussed, as well as moment redistribution and axial force distribution in the slab. Finally, the failure mode of the numerical model was examined.

\subsection{Load-Displacement Relation}

The load-displacement curves from the analyses were taken from a node with the same location as LVDT 2, in the exterior span where the largest deflection occurred, see Figure 1. A comparison of all the load-displacement curves from the numerical analyses and the experimental results measured by LVDT 2 is shown in Figure 7. The analyses with the lower tensile strength of $2.7 \mathrm{MPa}$ provided the best resemblance with the experimental load-deflection curve, although all models except number 3 showed relatively satisfactory results.

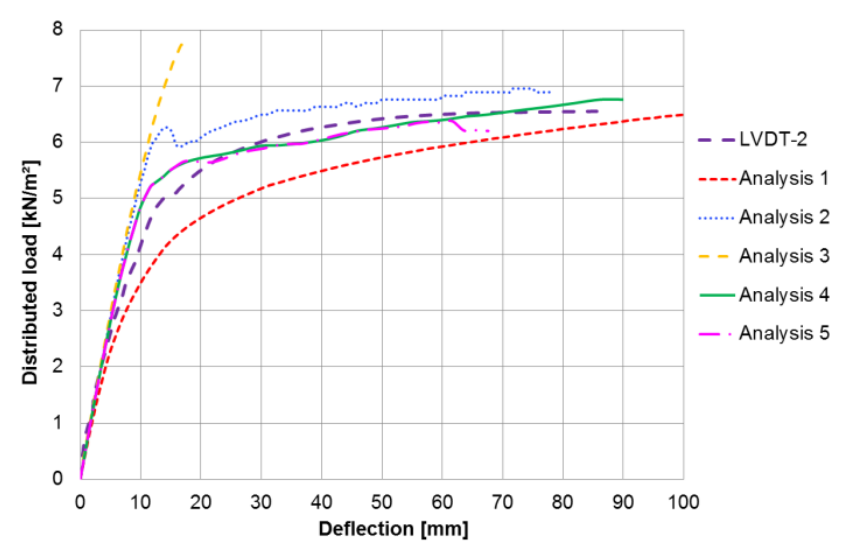

Figure 7. Load-displacement curve at midspan, all analyses

It is possible to optimise the tensile curves to resemble the experimental curve better, however, the aim of the study was not necessarily to find the exact load-displacement curve, but to investigate how the tensile parameters affected the response of the numerical model. In addition, it was desirable to use the results obtained from the bending tests, to find out whether they were representative for the model or not. In the following, the results from the various tensile models are shortly presented. The tensile curves are shown in Figure 6 and the results are presented in Figure 7.

Analysis 1, using a constant tensile curve, provided relatively good results, considering the highly idealised tensile behaviour. The load-displacement curve was, as expected, too soft and without any irregularities and there was no clear sign of failure from the response curve. The shape of the load-displacement curve shows relatively good resemblance with the experimental curve, but the analysis overestimated the deflections of the slab and conservative results were obtained. For design in service limit state, this analysis could provide sufficiently accurate results, as the curve does not deviate until it enters the nonlinear area and the deviation is on the safe side.

Analysis 2 was given a tensile strength of $3.8 \mathrm{MPa}$ and a negative slope of $E_{c, \text { neg }}=10000 \mathrm{MPa}$, a value suggested in [12]. Due to the sharp peak in this curve, obtaining convergence was problematic. The response from this analysis was too stiff, although the shape of the curve was satisfying. Cracking in the $\mathrm{x}$-direction was reached at a load of $5.1 \mathrm{kN} / \mathrm{m}^{2}$, which can be observed by a horizontal part in the experimental curve. For Analysis 2, the cracking in the span displayed at approximately $6.2 \mathrm{kN} / \mathrm{m}^{2}$, and was followed by unloading before the load increased again. The analysis was continued until it reached the same deflection as the experiment, but for the last part of the curve numerical problems occurred and this part will be disregarded in the further investigation.

Analysis 3 had a tensile curve with a tensile strength of 3.8 MPa but a gentler post-peak slope. This implied that the strain energy of this tensile model was about twice as large as for Analysis 2, and the response curve became nearly linear. This alternative was not further investigated, but was included to show how sensitive the model proved to be to changes in the tensile curve.

Analysis 4 was given a tensile strength of $2.7 \mathrm{MPa}$, which is lower than indicated by the bending tests, but the shape of the tensile curve resembled the bending test curves well. This analysis showed the best correspondence with the experimental curve and it experienced less numerical problems than Analysis 2. The load-displacement curve was too stiff in the beginning, but after a displacement of $20 \mathrm{~mm}$ it became too soft. The load capacity of this analysis was slightly underestimated, which was expected, as the tensile strength being used was lower than the strengths taken from the bending tests. Moreover, a multilinear descending branch, as opposed to a linear, did not seem to affect the results notably.

Analysis 5 had the same tensile curve as Analysis 4, but the curve descended to zero for the ultimate strain. The response curve was similar to the curve from Analysis 4 except unloading occurred after approximately $6.4 \mathrm{kN} / \mathrm{m}^{2}$, due to the added descending branch in the tensile curve. The results from Analysis 4 were not included in the further investigations.

From the analyses it can be concluded that the numerical model was relatively sensitive to changes made in the tensile constitutive model, especially when the strain energy was increased. Analysis 1, having a constant tensile curve with tensile strength equal to residual tensile strength, provided sufficiently accurate results for service limit state and the results were on the safe side. Except for Analysis 1, the models were too stiff and provided too low deflections at maximum load. All analyses were able to capture the ductile bending behaviour of the slab, and except from Analysis 3 the shape of load-displacement curves corresponded well with the experiment. 


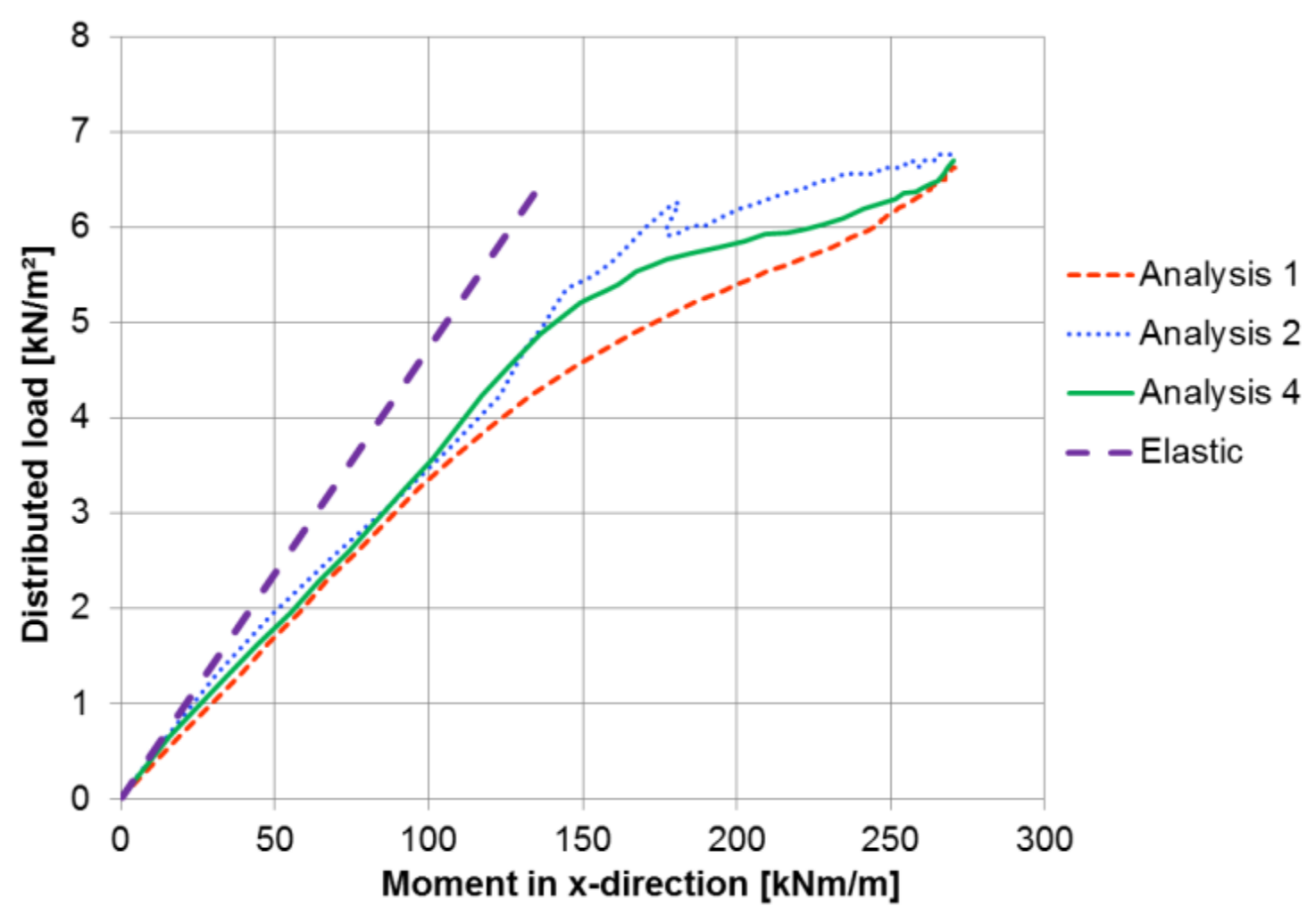

Figure 8. Moment in x-direction at interior column

\subsection{Moment Redistribution}

Significant moment redistribution occurred during the experiment, most likely being one reason why the slab obtained a higher load resistance than calculated. The most critical section was at the exterior span (see Figure 3) which was subjected to sagging moment in the $\mathrm{x}$-direction. Consequently, as the capacity was reached in the span, the loads redistributed to the supports. Analyses 1,2 and 4 were used to show the redistribution in the numerical model. In Figure 8 the distributed moments at the interior column are plotted against the water load and compared to a linear elastic analysis of the same slab model.

All the three nonlinear analyses displayed substantial moment redistribution to the supports, compared to the elastic analysis. However, the development and level of redistribution differed. Analysis 1 obtained the largest redistribution, while for Analysis 2, major redistribution occurred after cracking in the span, displayed by a dip in the curve. Analysis 4 showed something in between the other two. The values of the support moments from the analyses were unrealistically high, because the columns were modelled as point supports introducing singularities in the finite element model. Better ways to model the support is to model the column with solid elements or to use interface elements at the support area. The moment distribution would then be smoother and the peak moment from the point support would be reduced. Another indication of load redistribution is to investigate the reaction force at the support. During testing the load at the interior column was measured with a load cell showing a $30 \%$ reduction of the support load compared to an elastic solution. For the span, the moments found from nonlinear analyses did not deviate notably from the results of the elastic analysis.

\subsection{Distribution of Post-Tensioning Forces}

The distribution of axial forces from post-tensioning is of importance when designing post-tensioned flat slabs. The tendon layout used in this experiment was designed to obtain a one-way slab; it provided evenly distributed post-tensioning forces in the $\mathrm{x}$-direction and concentrated forces in the y-direction. Figure 9 shows the distributed axial forces in the $y$-direction, $\mathrm{N}_{\mathrm{yy}}$, from the concentrated tendons before applying the water pressure and at failure, respectively. The results were taken from Analysis 4 and the failure load was assumed to be $6.1 \mathrm{kN} / \mathrm{m}^{2}$. Figure $9 \mathrm{~A}$, displaying $\mathrm{N}_{\mathrm{yy}}$ due to post-tensioning only, shows that the concentrated tendons applied compression to nearly the entire slab. However, $\mathrm{N}_{\mathrm{yy}}$ was highly concentrated at the anchors, where the post-tensioning was applied as an external force. During loading, $\mathrm{N}_{\mathrm{yy}}$ increased above the interior column, which presumably was an effect of membrane forces in the slab caused by the water load. $\mathrm{N}_{\mathrm{yy}}$ increased only in a limited area close to the tendons, as seen in Figure 9B. The failure zones at the interior column strip and in the exterior span can also be seen in Figure 9B, displaying a decrease of pre-stressing in the respective zones. The axial forces in the x-direction applied by the distributed tendons, $\mathrm{N}_{\mathrm{xx}}$, were as expected nearly constant across the slab and throughout the loading scheme. 


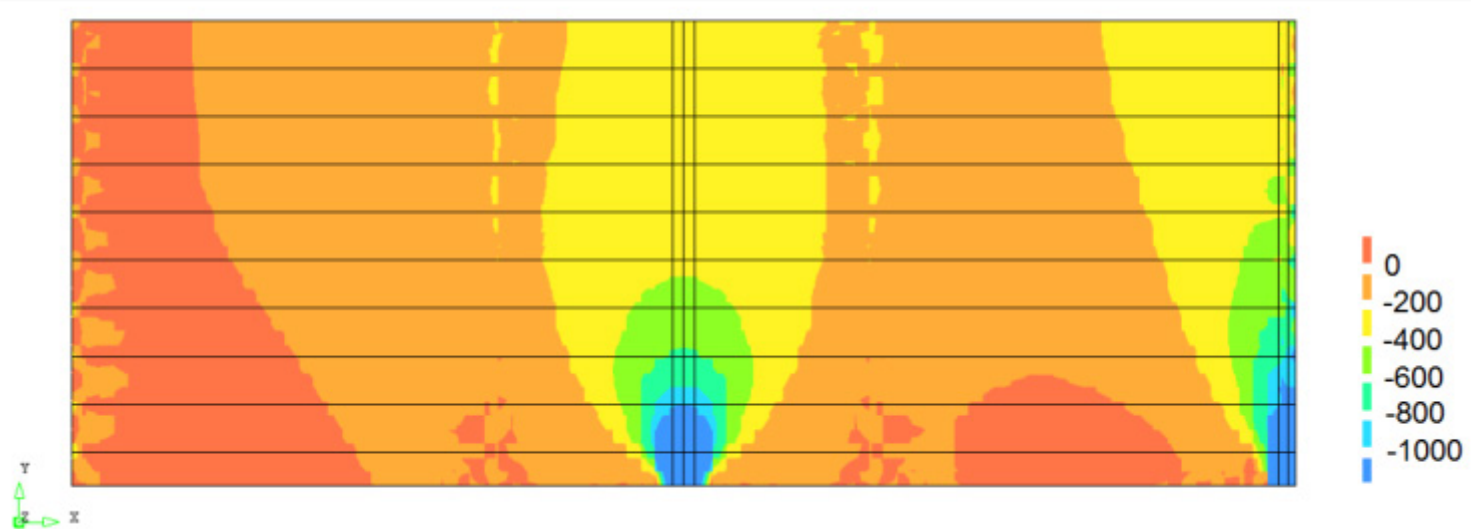

A

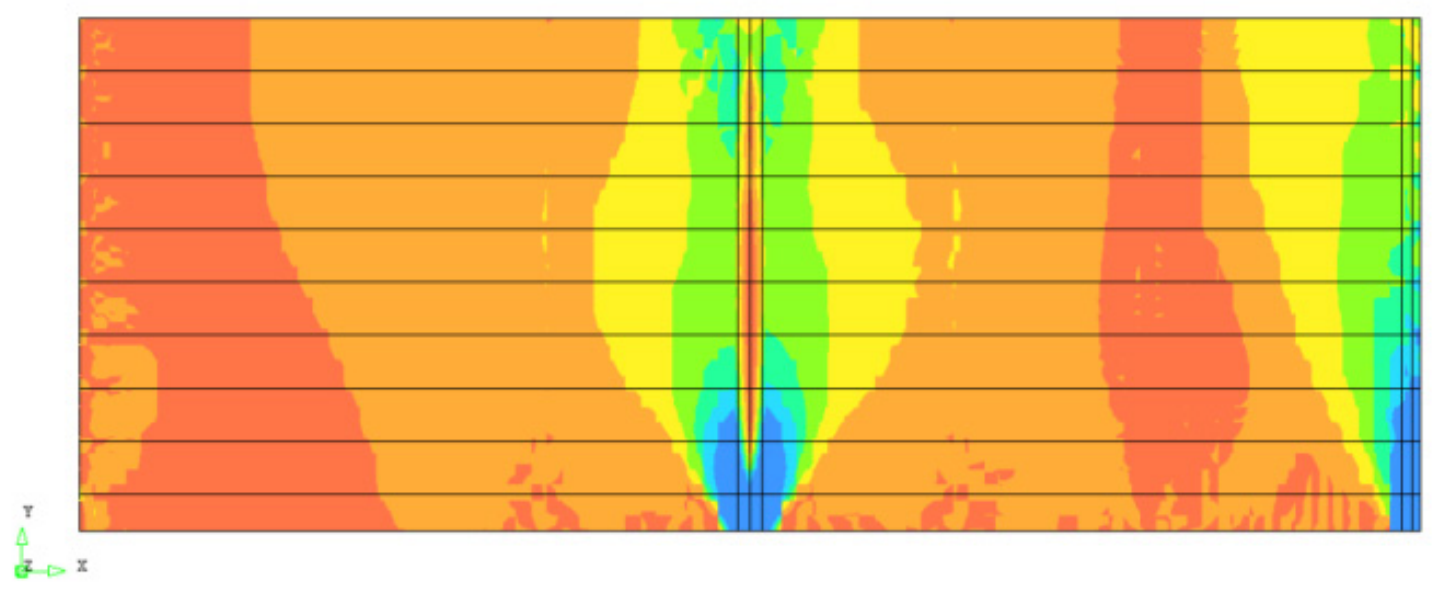

Figure 9. Distribution of axial forces $\mathrm{N}_{\mathrm{yy}}$ in the slab $[\mathrm{kN} / \mathrm{m}]$, Part A without water, Part B water pressure of $6.1 \mathrm{kN} / \mathrm{m}^{2}$

\subsection{Failure Mode}

All the analyses were capable of displaying the failure behaviour with yield lines in the exterior span and above the interior column. Analysis 1 did not display a distinct point of failure, but for analyses 2 and 4 the failure modes were further investigated. The strains in $\mathrm{x}$-direction were taken from an element with the same location as LVDT 1 (see Figure 1), at the bottom of the slab, and plotted over the load steps, see Figure 10. The results from analyses 2 and 4 show that for both models there was a clear load level at which the strains increased extensively without the load increasing, indicating that major crack propagation and eventually failure occurred. Thus the failure loads from analyses 2 and 4 were assumed to be $6.8 \mathrm{kN} / \mathrm{m}^{2}$ and $6.1 \mathrm{kN} / \mathrm{m}^{2}$, respectively.

The failure modes and crack patterns from analyses 2 and 4 were very similar, except for different failure loads, thus only results from Analysis 2 are included in the following. Figures 11 and 12 show the failure mode for Analysis 2 in terms of principal tensile strains and crack patterns, respectively. From Figure 11 it can be seen that the numerical model provided the correct failure mode for the slab (see Figures 3 and 4), and by plotting the principal tensile strains, the localisation of the failure zones was clearly visualised. The plots display tensile strains larger than 0.001 , which is the area in the tensile model where the fibre contribution dominates the post-cracking behaviour of SFRC and the tensile stress equals the residual tensile strength. The plots also show large strain concentrations and cracks arising around the columns, especially the interior column, but this did not initiate failure.

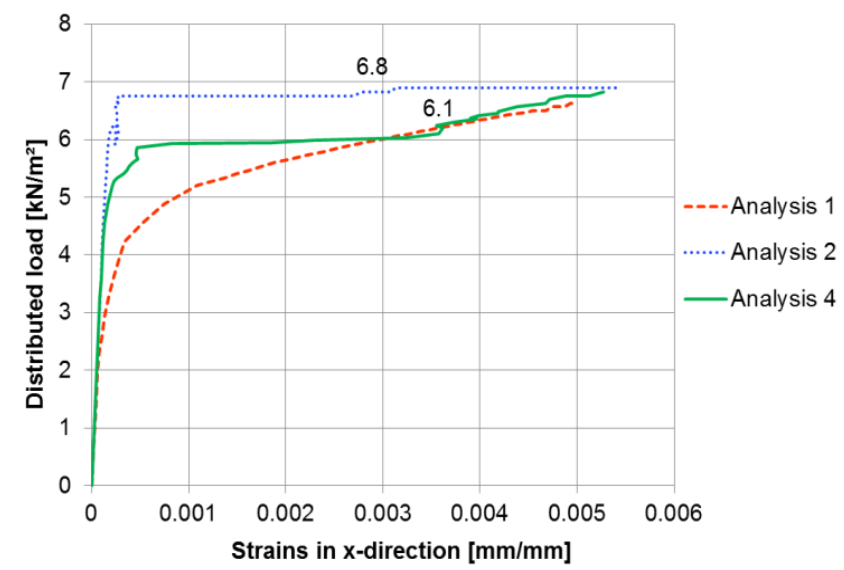

Figure 10. Development of strains in $x$-direction at outer span (bottom) 


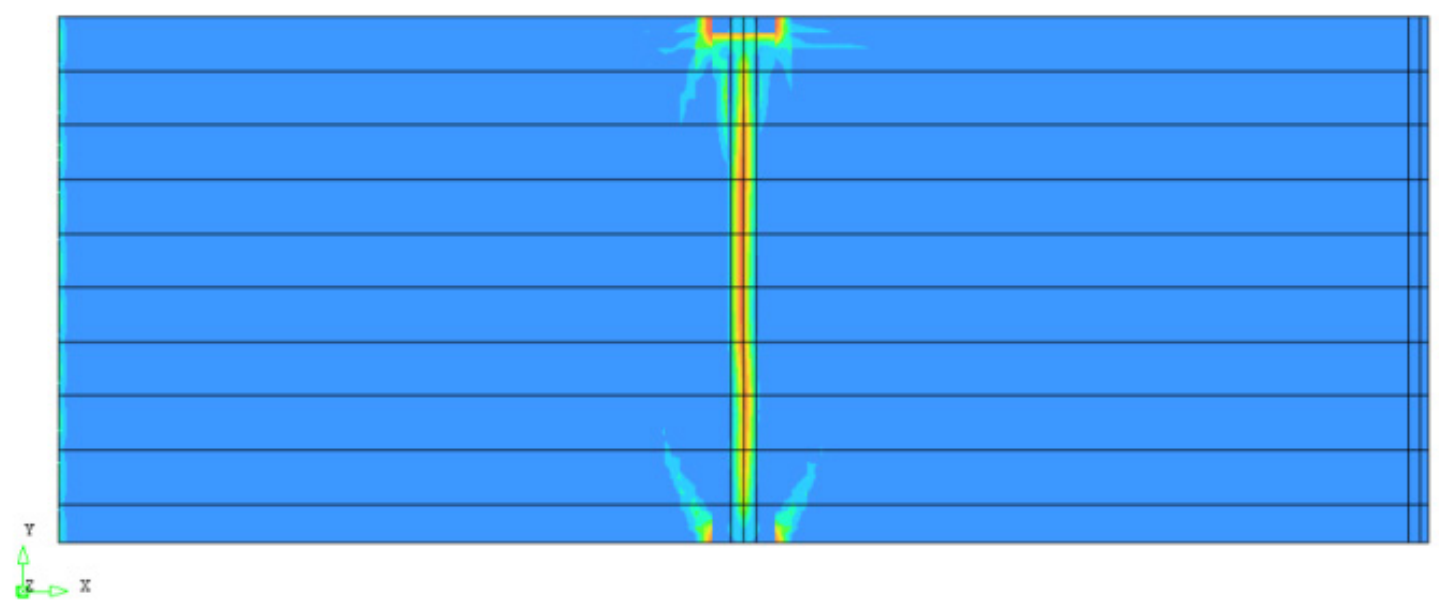

A



B

Figure 11. Principal tensile strains at failure load, Analysis 2. Part A at the top. Part B at bottom

When using a smeared crack model, cracks will generally be distributed over a large area, and crack localisation may not be properly displayed if the finite elements are too large. Figure 11 shows crack patterns of the model at failure, and it is seen that the cracks are distributed over a large area and the crack patterns are not in correspondence with the plots in Figure 11. However, the crack patterns show that at failure, the large localised cracks causing the collapse of the slab had already developed (seen as areas without cracks where the yield lines were located), and crack propagation beyond these lines was present.

The deflections from both analyses 2 and 4 were too low at failure, compared to the experiment. The experimental slab endured deflections up to $90 \mathrm{~mm}$ before collapsing, while the maximum deflection caused by the water load at failure was $60 \mathrm{~mm}$ and $43 \mathrm{~mm}$ for Analysis 2 and 4, respectively. When the slab in the experiment was deformed in the critical span, the water load in this area increased correspondingly, as the volume of the water increased. Assuming a triangular displacement shape following the yield lines in Figure 3 and a maximum deflection of $90 \mathrm{~mm}$, the additional uniform water load due to the deformation is approximately $0.45 \mathrm{kN} / \mathrm{m}^{2}$. This effect was not included in the numerical analyses, and may be one explanation why the deflections from the analyses were too small. Also, finite element solutions tend to be too stiff, as they contain too many constraints. The deflection shape from Analyses 2 is shown in Figure 13. When comparing to the failure of the experiment, shown in Figure 2, Analysis 2 displays good resemblance and the same yield line mechanism. 


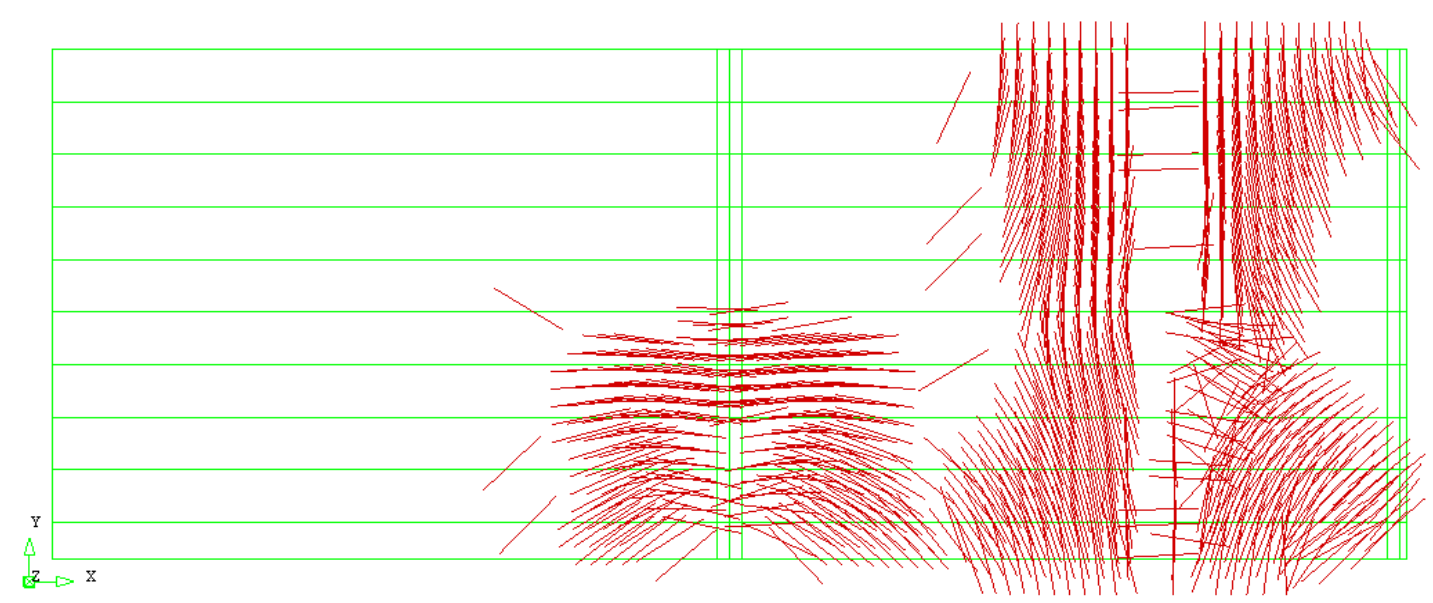

A

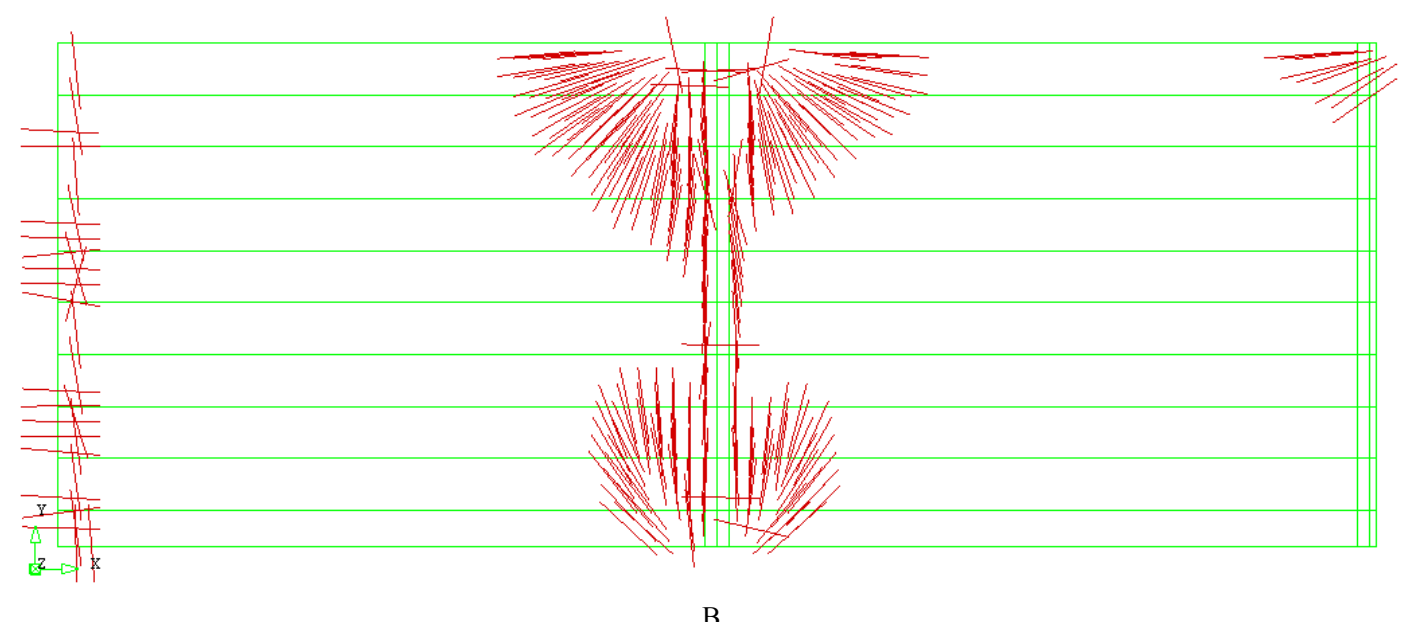

B

Figure 12. Crack pattern at failure load, analysis 2. Part A at the bottom. Part B at top

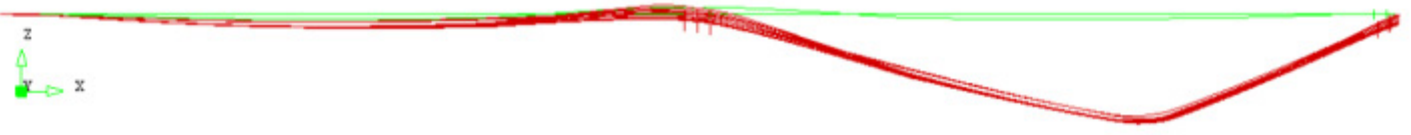

Figure 13. Deflection at failure for Analysis 2

\section{Conclusions}

The numerical model was capable of capturing the ductile bending behaviour of the slab and to display the correct failure mode, and the load-displacement curves corresponded well with the experiment. Significant moment redistribution was displayed, from the most critical section in the exterior span to the columns. Furthermore, the contribution of the steel fibre was captured by the finite element model due to the implemented tensile behaviour of the SFRC, containing the residual tensile strength. The parameter study of the tensile properties of SFRC showed that the finite element model was relatively sensitive to the tensile model, especially when the strain energy of the system was increased. However, the deviation between the response curves from the experiment and the analyses was not prominent until the nonlinear area of the load-displacement curves was entered, and for service limit state the change in tensile model had little impact. For the ultimate limit state, however, the tensile model used is of significance. The concept of replacing conventional longitudinal reinforcement with steel fibres shows promising results. In addition to efficiency and reduced cost during construction, the structure has sufficient ductility in ultimate limit state.

\section{REFERENCES}

[1] I. Løfgren. Fibre-reinforced concrete for industrial construction - a fracture energy approach to material testing and structural analysis. PhD thesis, Gothenburg, Sweden, Chalmers University of Technology, 254 s. : ill.,2005. 
[2] V. Gribniak, G. Kaklauskas, A. K. Hung Kwan, D. Bacinskas, D. Ulbinas. Deriving stress-strain relationships for steel fibre concrete in tension from tests of beams with ordinary reinforcement. Engineering Structures, Vol 42,387-95, 2012.

[3] fib. Model Code 2010: Final draft. Lausanne, Switzerland, International Federation for Structural Concrete (fib),2012.

[4] T. Kanstad, D. A. Juvik, A. Vatnar, A. E. Mathisen, S. Sandbakk, H. Vikan, E. Nikolaisen, Å. L. Døssland, N. Leirud, G. O. Overrein. Proposal for norwegian guidelines for design, execution and control of fibre reinforced concrete. COIN Project report 29, Norway, (in Norwegian), SINTEF Building and Infrastructure, 60,2011.

[5] Standards Norway. NS-EN 14651:2005+A1:2007. Test method for metallic fibre concrete - Measuring the flexural tensile strength (limit of proportionality (LOP), residual). Lysaker, Standards Norway,2008.

[6] P. Soroushian, C.-D. Lee. Distribution and orientation of fibers in steel fiber reinforced concrete. ACI Materials Journal, Vol 87,433-9, 1990.

[7] P. Stähli, R. Custer, J. G. M. Van Mier. On flow properties, fibre distribution, fibre orientation and flexural behaviour of FRC. Materials and Structures/Materiaux et Constructions, Vol 41,189-96, 2008.

[8] S. Foster. The application of steel-fibres as concrete reinforcement in Australia: from material to structure. Materials and Structures, Vol 42,1209-20, 2009.

[9] J. Tejchman, J. Kozicki. Experimental and theoretical investigations of steel-fibrous concrete, Springer; 2010.

[10] T. Kanstad, S. Sandbakk, M. R. Geiker, T. A. Martius-Hammer. Flowable fibre reinforced concrete: Materials development, fibre distribution and structural properties. Concrete Under the Northern Lights, Vol,55-65, 2013.

[11] J. Michels, D. Waldmann, S. Maas, A. Zürbes. Steel fibers as only reinforcement for flat slab construction - Experimental investigation and design. Construction and Building Materials, Vol 26,145-55, 2012.

[12] Å. L. Døssland. Fibre reinforcement in load carrying concrete structures: laboratory and field investigations compared with theory and finite element analysis, $\mathrm{PhD}$ thesis, Norwegian University of Science and Technology, Trondheim, Norway, 2008.
[13] S. Sandbakk. Fibre reinforced concrete: Evaluation of test methods and material development, $\mathrm{PhD}$ thesis, Norwegian University of Science and Technology, Trondheim, Norway, 2011.

[14] A. M. Brandt. Fibre reinforced cement-based (FRC) composites after over 40 years of development in building and civil engineering. Composite Structures, Vol 86,3-9, 2008.

[15] E. Vidal Sarmiento, G. Zirgulis, S. Sandbakk, M. R. Geiker, T. Kanstad. Influence of concrete flow on fibre distribution, orientation and mechanical properties of fibre reinforced concrete. BEFIB2012 - 8th RILEM International Symposium of Fibre Reinforced Concrete, Rilem publications, 119-20, 2012.

[16] TNO DIANA BV. DIANA Finite element analysis Release 9.4. The Netherlands, TNO DIANA BV,2012.

[17] M. A. Hallberg, H. E. Hanssen. Post-rensioned fibre reinforced flat slab., MSc thesis, Norwegian University of Science and Technology, Norway, Department of Structural Engineering, 2013.

[18] KrampeHarex. Online available from www.krampeharex.com/index.php?id=1696

[19] Standards Norway. NS-EN 1992-1-1:2004+NA:2008. Eurocode 2: Design of concrete structures - General rules and rules for buildings, Norway, Standards Norway; 2008.

[20] J. Seehusen. Online available from http://www.tu.no/bygg/2013/05/27/forskalingen-ga-fra-seg-e t-langt-pinefullt-skrik

[21] J. Barros, J. Figueiras. Flexural Behavior of SFRC: Testing and Modeling. Journal of Materials in Civil Engineering, Vol 11,331-9, 1999.

[22] S.-K. Woo, K.-J. Kim, S.-H. Han. Tensile cracking constitutive model of Steel Fiber Reinforced Concrete (SFRC). KSCE Journal of Civil Engineering, Vol 18,1446-54, 2014.

[23] RILEM TC 162-TDF. $\sigma$ - $\varepsilon$-Design Method. Materials and Structures, Vol 36,560-7, 2003.

[24] A. Hillerborg, M. Modéer, P. E. Petersson. Analysis of crack formation and crack growth in concrete by means of fracture mechanics and finite elements. Cement and Concrete Research, Vol 6,773-81, 1976. 